\title{
Instrumental measurement of odour nuisance in city agglomeration using electronic nose
}

\author{
Bartosz Szulczyński ${ }^{1, *}$, Tomasz Dymerski ${ }^{2}$, Jacek Gębicki ${ }^{1}$ and Jacek Namieśnik ${ }^{2}$ \\ ${ }^{1}$ Department of Chemical and Process Engineering, Faculty of Chemistry, Gdansk University of \\ Technology, 11/12 G. Narutowicza Str., 80-233 Gdańsk, Poland \\ ${ }^{2}$ Department of Analytical Chemistry, Faculty of Chemistry, Gdansk University of Technology, \\ 11/12 G. Narutowicza Str., 80-233 Gdańsk, Poland
}

\begin{abstract}
The paper describes an operation principle of odour nuisance monitoring network in a city agglomeration. Moreover, it presents the results of investigation on ambient air quality with respect to odour obtained during six-month period. The investigation was carried out using a network comprised of six prototypes of electronic nose and Nasal Ranger field olfactometers employed as a reference method. The monitoring network consisted of two measurement stations localized in a vicinity of crude oil processing plant and four stations localized near the main emitters of volatile odorous compounds such as sewage treatment plant, municipal landfill, phosphatic fertilizer production plant. The electronic nose prototype was equipped with a set of six semiconductor sensors by FIGARO Co. and one PID-type sensor. The field olfactometers were utilized for determination of mean concentration of odorants and for calibration of the electronic nose prototypes in order to provide their proper operation. Mean monthly values of odour concentration depended on the site of measurement and on meteorological parameters. They were within $0-6.0 \mathrm{ou} / \mathrm{m}^{3}$ range. Performed investigations revealed the possibility of electronic nose instrument application as a tool for monitoring of odour nuisance.
\end{abstract}

\section{Introduction}

Unpleasant odours are naturally associated with danger, feeling of discomfort and they can cause negative psychosomatic symptoms. Long-term exposure to odorous compounds with unpleasant odour can result in loss of pleasure in living in particular area or building, in extreme cases it can lead to persistent changes in human organism and to chronic diseases [1-2]. Nowadays unpleasant odours present in a vicinity of air pollution sources are one of the main reasons of the complaints on environment quality, including ambient air quality. The major reasons of the complaints include [3-5]:

- actual odour nuisance,

- too short distance between sources of emission of odorants with unpleasant odour and residential areas,

\footnotetext{
* Corresponding author: bartosz.szulczynski@pg.edu.pl
} 
- health hazard,

- lack of hermetization or deodorization of odour nuisance sources,

- increasing environmental concern among society.

Reduction or almost total elimination of emission of odorants with unpleasant odour become a priority for these branches of industry, the activity of which contributes to introduction of those compounds to ambient air. This reduction can consist in:

- prevention of emission of odorants with unpleasant character,

- introduction of suitable unit operations (absorption, adsorption, catalytic combustion, non-thermal combustion, biofiltration) to deodorization for existing industrial units,

- suitable planning of building and localization of new-built industrial units.

Independently of applied purification technology resulting in a limitation of emission of odorants characterized by unpleasant odour it is necessary to monitor the effectiveness of deodorization process via measurement of odour concentration at inlet and outlet of an installation [6-8]. The most popular techniques dedicated to this type of applications are olfactory techniques, especially dynamic olfactometry normalized in accordance with the standard EN 13725:2003 "Air quality. Determination of odour concentration by dynamic olfactometry". Sense of smell is a sensor allowing odour detection and evaluation of ambient air quality with respect to odour. Popularity of this technique is exemplified by the fact that it is the most often proposed measurement technique in these countries, which undertake the attempts of solving the problems connected with odour nuisance [9-13]. Apart from unquestionable advantages of this technique there are also certain drawbacks and inconveniences including:

- lack of on-line monitoring and ability to record short episodes of high concentration of odorants,

- need for qualified personnel (team of assessors) with suitable, regularly controlled odour perception,

- need for a laboratory with precisely defined parameters such as temperature, relative humidity as well as noise level.

In some cases dynamic olfactometry technique does not provide satisfactory results, for example in case of low odour concentrations (at the level of $1-50 \mathrm{ou} / \mathrm{m}^{3}$ ). It is also difficult to determine odour concentration upon short-lasting changes of emission over particular area. In these situations it seems more advantageous to apply field olfactory technique. This approach allows characterization of concentration of odorants with unpleasant odour present in ambient air via dilution of investigated air stream with odourless gas (air purified on carbon filters). Among many devices utilized for field olfactometry measurements the Nasal Ranger (St. Croix Sensory, USA) field olfactometer is the most frequently employed one.

Application of the instrumental techniques enabling on-line measurements would make it possible to conduct the measurements, which cannot be carried out with dynamic or field olfactometry techniques. For many years an electronic nose has been an instrumental tool, which fulfils this requirement. The electronic nose is defined as an analytical device intended for fast detection and discrimination of odorous substances mixtures due to imitation of human sense of smell. In case of the electronic nose an identification of gas mixture composition is possible thanks to excitation of all chemical sensors comprising the electronic nose. This excitation (sensor response in the form of analytically useful signal) occurs in every sensor with different extent. Such excitation yields characteristic set of signals from particular sensors called a response vector of sensor matrix or electronic nose [14-17].

The main cause of odour nuisance in city agglomerations is emission of volatile compounds characterized by unpleasant odour from such sectors of industrial activity as: utilization and disposal of municipal waste, sewage treatment plants, chemical plants, meat 
and crop processing plants [18]. In the Tri-city agglomeration under consideration apart from the aforementioned sources of emission of odorants with unpleasant odour there is also a crude oil processing plant. Even such superficial analysis of the emission sources over particular area reveals a need of creation of an aerial monitoring network employing electronic nose-type devices, which would provide reliable information to the society and industry about occurrence of odour nuisance hazard.

The authors of this paper would like to present the results of investigation on ambient air quality with respect to odour nuisance near municipal landfill, sewage treatment plant and crude oil processing plant, which were performed using designed and built odour nuisance monitoring network. The aim of the investigation was verification of variation in odour intensity depending on location of the measurement site and meteorological conditions during a six-month period. Moreover, usability of the electronic nose instrument for monitoring of ambient air with respect to odorants presence was examined.

\section{Experimental}

\subsection{Structure of electronic nose}

The measurement set-up consisted of: a Tecfluid flow meter, the prototype of electronic nose, a suction pump and a PC class computer. Volumetric flow rate of the ambient air sucked equalled $1 \mathrm{dm}^{3} / \mathrm{min}$. The prototype design involved a set of six commercial semiconductor sensors by FIGARO Co. (TGS 823, TGS 826, TGS 832, TGS 2600, TGS 2602, TGS 2603) and one photoionization sensor of PID-type (PPB MiniPID). Fig. 1 presents a block diagram of the electronic nose prototype.

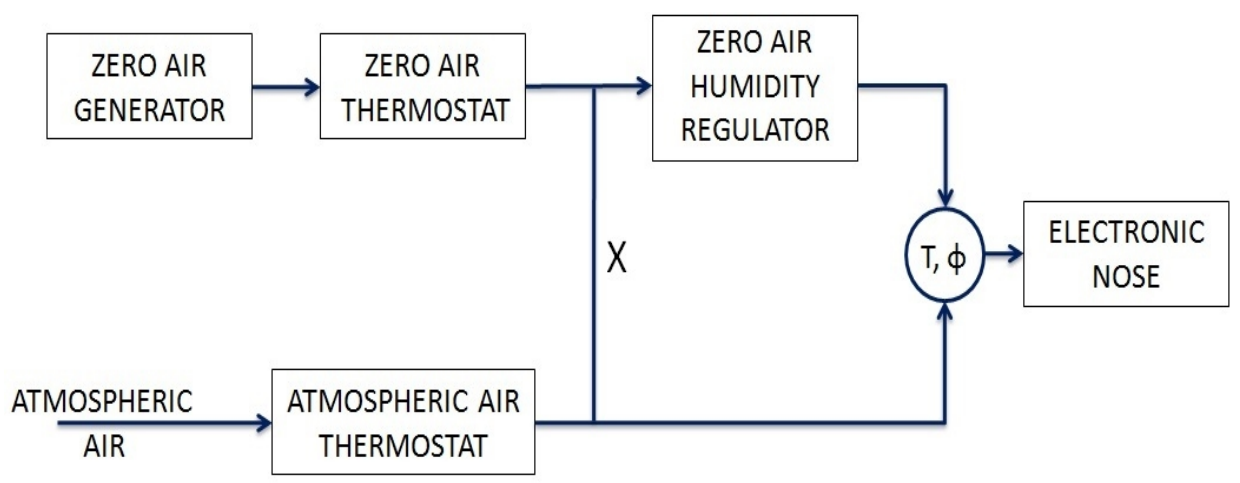

Fig. 1. Block diagram of electronic nose-type instrument. X-bypass, T-temperature sensor, $\phi$ humidity sensor.

An analogue-to-digital converter (ADC) was used to process an output signal from the sensor set of the prototype. The output signal was converted into digital form in the range from 0 to 16 bits. The values of particular sensor signal taken for data analysis originated from the range, where the sensor signal attained steady value (steady state).

The operation mode of the electronic nose was as follows:

- suction of ambient air - 1 min.,

- stop-flow and measurement - interruption of ambient air flow in the sensor chamber 0.5 min.,

- washing - zero air is passed through the entire pneumatic system in order to provide cleaning and stabilization of the sensors signals at the baseline signal level $-13.5 \mathrm{~min}$. 
Each cycle was followed by another repetition, so 4 measurements of odour concentration were performed during one hour.

\subsection{Odour nuisance monitoring network}

The monitoring network consisted of two measurement stations localized in a vicinity of the crude oil processing plant and four measurement stations localized near the main emitters of volatile odorous compounds such as sewage treatment plant, municipal landfill and phosphatic fertilizer production plant. Fig. 2 schematically presents distribution of six odour nuisance monitoring stations in the city agglomeration. Each of these stations was equipped with the e-nose type device and a system for data transmission to the central unit. Correct operation of the odour nuisance monitoring network required preliminary investigations of the electronic nose prototypes in field conditions supported with the field olfactometry tests treated as a reference method, with respect to which the electronic nose instrument was calibrated.

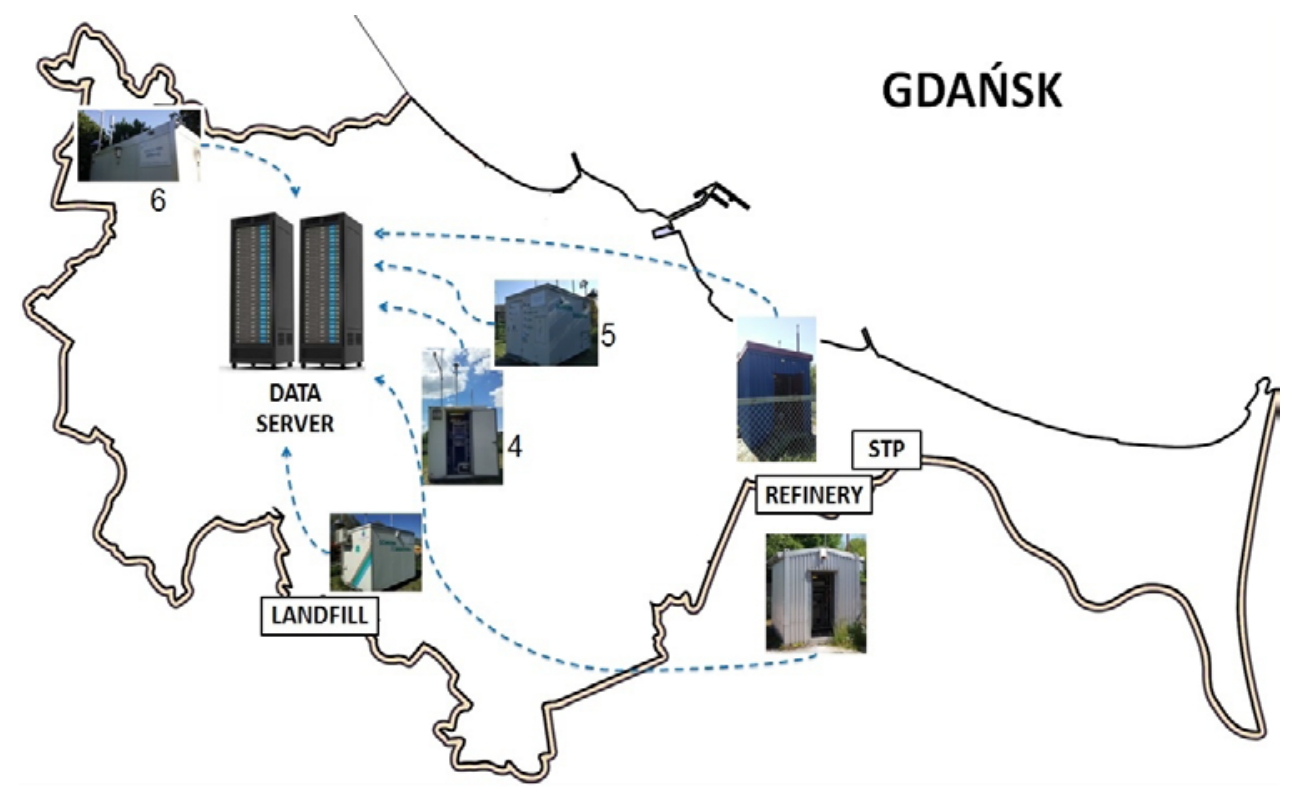

Fig. 2. Diagram of odour nuisance monitoring network in city agglomeration.STP-sewage treatment plant, 4,5,6 - Location of other measurement stations.

\subsection{Investigations using Nasal Ranger field olfactometer}

Four persons (a team of assessors) took part in the investigation carried out with the field olfactometers Nasal Ranger (St. Croix Sensory, USA). These persons were selected from a larger group following a standard procedure elaborated by the St. Croix Sensory, Inc. (St. Croix Sensory 2006). The aim of this procedure was selection of the assessors characterized by particular odour sensing threshold. Moreover, the assessors were trained with respect to sensory analysis using the field olfactometers. The measurements with field olfactometers allowed determination of $\mathrm{D} / \mathrm{T}$ values (dilution to sensing threshold), at which 
the odour was sensed. Based on the $\mathrm{D} / \mathrm{T}$ values it was possible to calculate individual odour concentration $\mathrm{c}_{\mathrm{od}, \mathrm{i}}$ at given measurement point using the following formula (1):

$$
c_{o d, i}=\sqrt{Z_{n o} \times Z_{y e s}}
$$

where: $Z_{n o}=D / T+1-D / T$ value, at which the odour is imperceptible prior to the $D / T$ value, at which odour is perceptible, $Z_{\text {yes }}=\mathrm{D} / \mathrm{T}+1-\mathrm{D} / \mathrm{T}$ value, at which the odour is perceptible following the $\mathrm{D} / \mathrm{T}$ value, at which the odour is imperceptible.

The value of odour concentration $\mathrm{c}_{\mathrm{od}}\left[\mathrm{ou} / \mathrm{m}^{3}\right]$ was calculated as a geometrical mean of the $\mathrm{n}$ set of all individual odour concentrations $\mathrm{c}_{\mathrm{od}, \mathrm{i}}$ for a given measurement point using the formula (2):

$$
c_{o d}=\sqrt[n]{c_{o d, 1} \times c_{o d, 2} \times c_{o d, 3} \times \ldots \times c_{o d, n}}
$$

where: $\mathrm{c}_{\mathrm{od}, \mathrm{n}}$ is the individual odour concentration provided by a given panellist.

\subsection{Calibration of electronic nose instrument with respect to field olfactometer}

The signals obtained from particular sensors were subjected to statistical analysis in order to eliminate statistically insignificant signals. Then statistically significant signals were used to determine a ratio of sensor signal change $\Delta S$ to reference signal $S_{0}$ and the value of mean geometric signal was calculated using the formula (3):

$$
\text { Signal }=\sqrt[n]{S_{1} \times S_{2} \times S_{3} \times \ldots \times S_{n}}
$$

In the next step the calculated value was compared with the value of mean odour concentration determined by the team of assessors using Nasal Ranger field olfactometers. A series of analysis enabled calibration of the electronic nose instrument in the range from 0 to $25 \mathrm{ou} / \mathrm{m}^{3}$. Generally, a process of sensor signal conversion into odour concentration can be presented with the scheme illustrated in Fig. 3 .

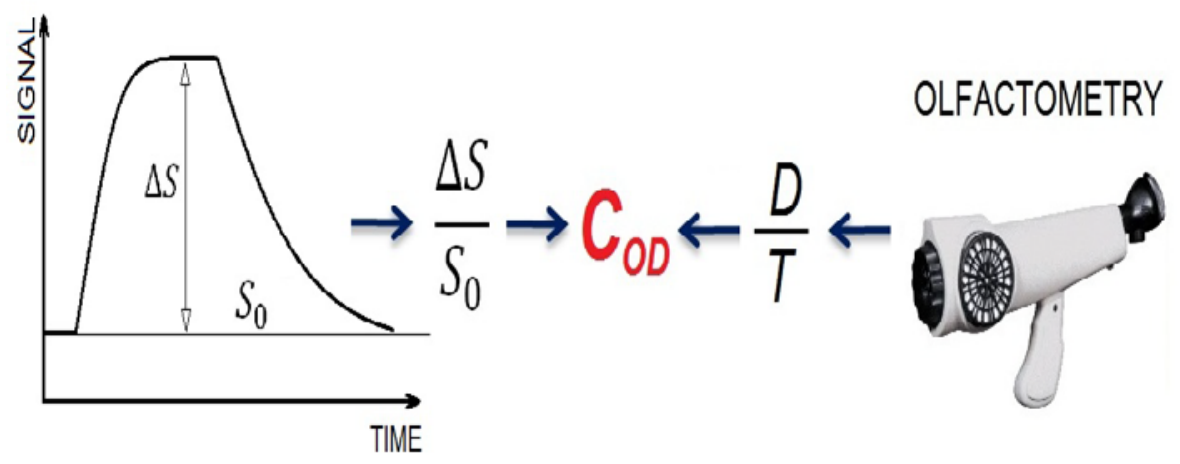

Fig. 3. Process of sensor signal conversion into odour concentration.

\section{Results}


Fig. 4 presents the changes of mean odour concentration versus time and localization of the measurement station. During the six-month time span it can be seen that higher odour concentrations occur in the summer season. As far as localization of the measurement station is concerned, the highest odour concentrations are noticed over the area neighbouring the municipal landfill, then next to the sewage treatment plant and finally in a vicinity of the crude oil processing plant. A range of mean odour concentration observed in a vicinity of the municipal landfill was from $2.5 \mathrm{ou} / \mathrm{m}^{3}$ to $6.0 \mathrm{ou} / \mathrm{m}^{3}$. Corresponding range in case of the sewage treatment plant was from $2.0 \mathrm{ou} / \mathrm{m}^{3}$ to $4.3 \mathrm{ou} / \mathrm{m}^{3}$. A range of mean odour concentration for the area next to the crude oil processing plant was from $1.9 \mathrm{ou} / \mathrm{m}^{3}$ to $3.7 \mathrm{ou} / \mathrm{m}^{3}$. In the remaining measurement points mean odour concentration varied between 0 and $2.3 \mathrm{ou} / \mathrm{m}^{3}$.

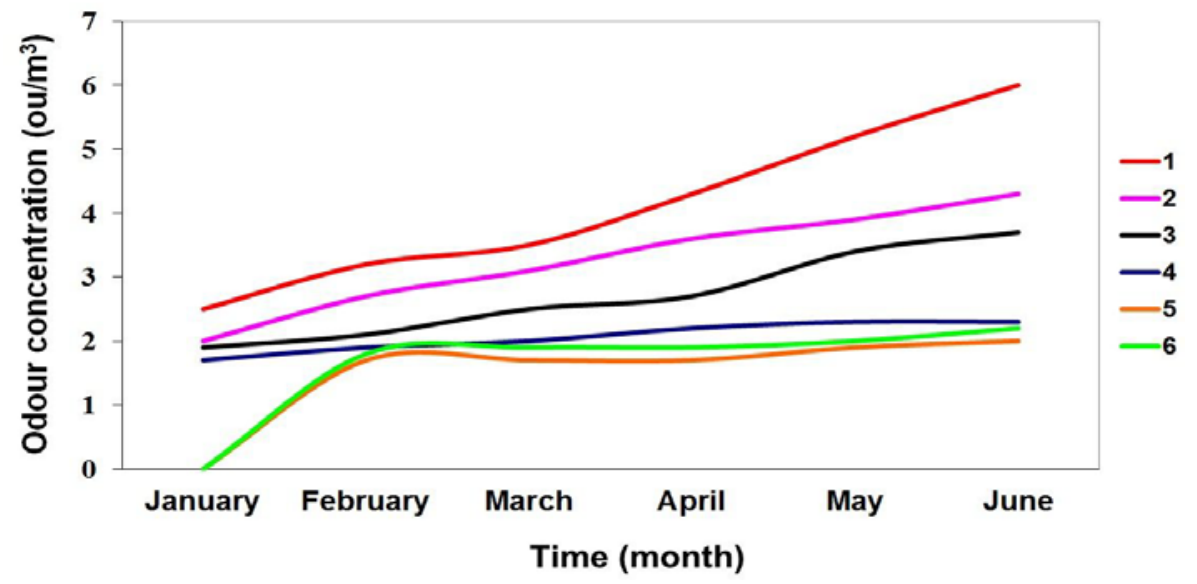

Fig. 4. Changes of mean odour concentration versus time and localization of measurement station. 1landfill, 2-sewage treatment plant, 3-refinery, 4,5,6-other measurement stations.

Table 2 shows the dependences between the maximum odour concentration and time as well as localization of the measurement station. Also here it can noticed that the highest concentrations occurred in the summer season and the values of concentration were also dependent on localization of the measurement station. The highest odour concentration was observed in June at the station localized near the municipal landfill. Its value was equal $24.0 \mathrm{ou} / \mathrm{m}^{3}$.

Table 1. Dependence between maximum odour concentration and time as well as localization of measurement station.

\begin{tabular}{|c|c|c|c|c|c|c|}
\hline & \multicolumn{6}{|c|}{ maximum odour concentration } \\
\hline $\begin{array}{c}\text { measurement } \\
\text { station }\end{array}$ & January & February & March & April & May & June \\
\hline landfill & 7.2 & 8.4 & 10.2 & 14.1 & 17.2 & 24.0 \\
\hline $\begin{array}{c}\text { sewage treatment } \\
\text { plant }\end{array}$ & 4.5 & 5.8 & 8.0 & 11.2 & 13.5 & 17.4 \\
\hline refinery & 3.0 & 4.5 & 5.6 & 5.8 & 6.7 & 7.4 \\
\hline $4,5,6$ & 1.7 & 2.5 & 3.5 & 4.2 & 5.5 & 5.9 \\
\hline
\end{tabular}


This situation was probably caused by the chemical and biological processes occurring inside waste piles, which can be treated as a bioreactor. An increase in temperature contributed to acceleration of the microbiological and biochemical processes generating significant amount of volatile compounds, including those malodorous ones. These processes yield the products of anaerobic denitrification and desulphurization. In case of the sewage treatment plant there is intensification of digestion processes. In case of the crude oil processing plant it is probable that an increase in ambient air temperature contributes to enhanced sweating of tanks, leakages of valves, pipelines and to non-organized emission. These factors can influence on increased emission of malodorous compounds.

Fig. 5. illustrates the changes of mean odour concentration versus relative humidity of ambient air for three measurement stations characterized by the highest odour concentrations during a given measurement period (the stations localized in a vicinity of municipal landfill, sewage treatment plant and crude oil processing plant). It can be noticed that the values of mean odour concentration decrease with an increase in ambient air relative humidity. Most probably it is caused by a phenomenon of sorption and absorption of odorous compounds on and inside water vapour droplets (fog), hence a wet deposition occurs, which results in a decrease in odour concentration level in ambient air [19].

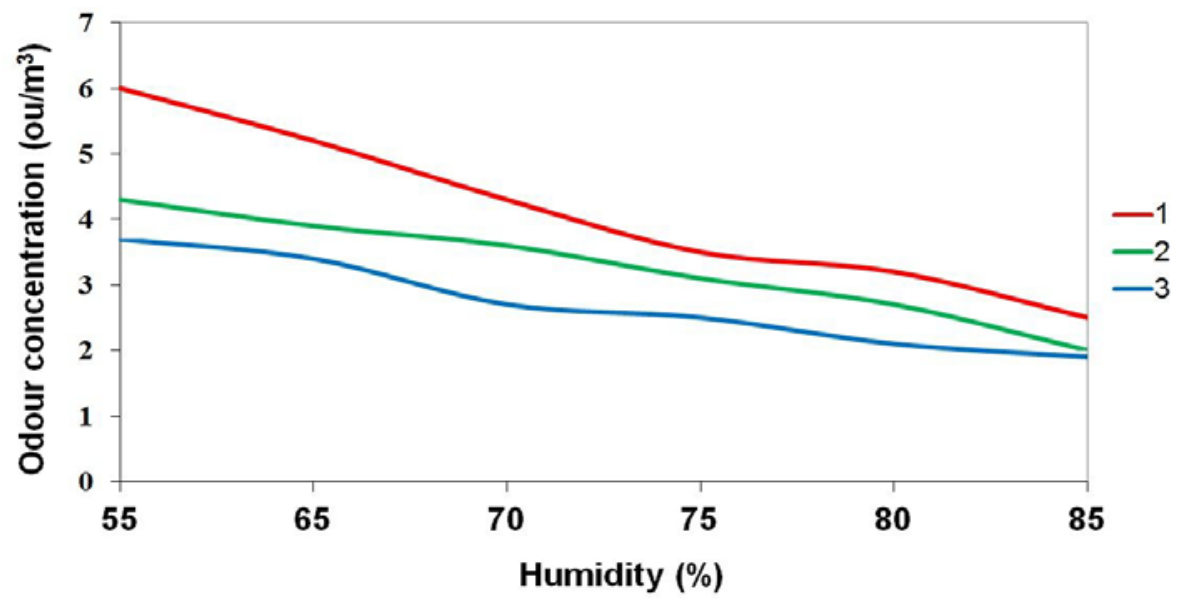

Fig. 5. Changes of mean odour concentration versus relative humidity of ambient air for three measurement stations characterized by the highest odour concentrations over given area. 1-landfill, 2sewage treatment plant, 3-refinery.

\section{Summary}

The investigations of odour concentration level in a vicinity of the main sources of odorants emission in the city agglomeration, performed with the electronic nose-type instruments revealed variation of odour concentration depending on the time of year and the measurement site. The area near the municipal landfill was characterized by the highest mean as well as maximum odour concentrations. It was also observed that the value of odour concentration over given area depended on climatic conditions. An increase in temperature and a decrease in relative humidity of ambient air are associated with an increase in odour concentration. Reverse situation occurred for a decrease in temperature and an increase in relative humidity of ambient air. Proper operation of the electronic nose depended on its calibration with respect to the field olfactometry measurements. Obtained completeness of measurement results was at the level of $60 \%$. The obtained mean odour concentration are in the range of 1 to $6 \mathrm{ou} / \mathrm{m}^{3}$. This indicates that the European standard of 
some countries has been exceeded. Work on the proper functioning of the electronic nose used to monitor air quality for odor compounds should be continued and more and more sensitive chemical sensors should be added to these devices.

The investigations were financially supported by the Grant No. PBSII/B9/24/2013 from the National Centre for Research and Development and the Grant No. UMO-2015/19/B/ST4/02722 from the National Science Centre.

\section{References}

1. M. Kampa, E. Castanas, Environ. Pollut. 151, 362-367 (2008)

2. V. Naddeo, T. Zarra, S. Giuliani, V. Belgiorno, Chem. Eng. Trans. 30, 85-90 (2012)

3. I. Sówka, P. Sobczyński, U. Miller, Rocz. Ochr. Sr. 17, 1339-1349 (2015)

4. J.A. Nicell, Atmos. Environ. 43, 196-206 (2009)

5. M. Trincavelli, S. Coradeschi, A. Loutfi, Sens. Actuators B-Chem. 139, 265-273 (2009)

6. L. Capelli, S. Sironi, R. Del Rosso, J.M. Guillot, Atmos. Environ. 79, 731-743 (2013)

7. L. Capelli, S. Sironi, R. Del Rosso, P. Centola, Water Res. 43, 7, 1977-1985 (2009)

8. C. Alfonsín, R. Lebrero, J.M. Estrada, R. Munoz, N.J.R. Kraakman, G. Feijoo, M.T. Moreira, J. Environ. Manage. 149, 77-84 (2015)

9. A.H. Bokowa, 2010, Chem. Eng. Trans. 23, 31-36 (2010)

10. L. Capelli, S. Sironi, R. Barczak, M. Il Grande, R. Del Rosso, Water Sci. Technol. 66, 1607-1613 (2012)

11. J.M. Guillot, Chem. Eng. Trans. 30, 295-300 (2012)

12. I. Sówka, Environ. Prot. Eng. 36, 2, 133-141 (2010)

13. L. Capelli, S. Sironi, R. Del Rosso, P. Centola, S. Bonati, Water Sci. Technol. 61, 1267-1278 (2010)

14. A.D. Wilson, M. Baietto, Sensors 9, 5099-5148 (2009)

15. J. Gębicki, T. Dymerski, J. Namieśnik, Environments 4, 1, 7 (2017)

16. R. Munoz, E.C. Sivret, G. Parcsi, R. Lebrero, X. Wang, I.H. Suffet, R.M. Stuetz, Water Res. 44, 5129-5149 (2010)

17. B. Szulczyński, J. Gębicki, Environments 4, 1, 21 (2017)

18. J. Gębicki, T. Dymerski, J. Namieśnik, Environ. Prot. Eng. 42, 2, 97-106 (2016)

19. H. Byliński, P. Kolasińska, T. Dymerski, J. Gębicki, J. Namieśnik, Monats. Chem. 148, 9, 1651-1659 (2017) 